\title{
Proximal gastric vagotomy after five years
}

\author{
D W STOREY, P B BOULOS, M W N W R D, AND C G CLARK * \\ From the Department of Surgery, School of Medicine, University College London, London
}

SUMMARY A follow-up of 93 patients with chronic duodenal ulceration treated by proximal gastric vagotomy without drainage five to nine years previously shows a high incidence of confirmed recurrent ulceration of $16.1 \%$. In addition, there have been patients with transient recurrent ulceration, and a small group with persistent dyspeptic symptoms but in whom no ulcer has been demonstrated. The operation is commendable for its lack of side-effects, but the high incidence of recurrent or persistent symptoms may lead to some reservations about its general application in the treatment of chronic duodenal ulceration.

The operation of proximal gastric vagotomy without draınage (highly selective vagotomy, parietal cell vagotomy) has now been in use for 11 years. It is designed to achieve adequate denervation of the parietal cell mass with minimal disturbance of gastric function, and is a logical attractive extension of the approach to the treatment of duodenal ulcer introduced by Dragstedt. ${ }^{1}$ There is little doubt that the incidence of diarrhoea and dumping is less with proximal gastric vagotomy than after other procedures ${ }^{24}$ and on this basis it has been proposed that it should replace truncal vagotomy and drainage as the elective operation of choice for chronic, uncomplicated duodenal ulceration. The wisdom of this policy depends upon whether the initial good results reported by Johnston and Amdrup" can be repeated by other surgeons, and whether the recurrence rate remains satisfactory as the length of experience grows.

This report presents the results of operation five to nine years later and examines the results of the few series of similar duration.

\section{Methods}

P A T I E N T S

From January 1970 to June 1974 , a total of 120 patients with chronic duodenal ulcer were treated electively by proximal gastric vagotomy without

* Address for correspondence and requests for reprints: Professor C G Clark, Department of Surgery, School of Medicine, University College London, University Street, London WCIE 6JJ.

Received for publication 28 January 1981 drainage. These were a selected group, for in the same period another 119 patients with duodenal ulcer had one of the alternative operative procedures. Proximal gastric vagotomy was not used for patients with bleeding ulcers or pyloroduodenal stenosis, or in those who were obese or where adhesions obscured the lesser omentum. Proximal gastric vagotomy was also avoided in those who were unlikely to attend follow-up, but, despite this precaution, 24 patients were subsequently lost to follow-up before five years had elapsed. Another three died of causes unrelated to ulcer and operation. There was no operative mortality. The remaining 93 patients considered here comprise 70 males and 23 females with a mean age of 44 for both sexes (age range 19-81 years).

The duration of ulcer symptoms was more than 10 years in 45 patients, between two and 10 years in 43 and less than two years in only five. Twentyone had had previous haemorrhage and three had had previous perforation. Medical treatment had failed in all. Diagnosis was based on radiological studies until fibreoptic endoscopy was established in 1972 .

The details of operative technique were not constant over the period, or from one operator to another (there were five operators--two consultants and three senior registrars). In most cases, however, the dissection of the lesser curvature was limited distally by anatomical considerations - that is, denervation started just to the left of the point where the apparent continuation of the nerve of Latarjet crossed the lesser curvature. 
The ocsophageal dissection was less extensive in the early part of the series-2-3 $\mathrm{cm}$ as opposed to the 5-6 cm now considered advisable." Intraoperative methods of testing the completeness of valgotomy were used.

After operation, patients attended the gastric follow-up clinic. The assessment included a uniform system of specific symptom interrogation. The mean follow-up of the 93 patients is 6.7 years. The investigation of patients with significant symptoms included endoscopy.

\section{Results}

Twenty-four of the patients had evidence of recurrent peptic ulcer disease. These have been divided into three groups.

(; R O U P A

In this group there were 15 patients $(16 \cdot 1 \%)$ with unequivocal recurrent ulceration. The onset of recurrent symptoms was within the first two years in eight patients, one of whom perforated his ulcer one month after surgery. (He was treated by simple oversew and is well on no treatment eight years later.) In the rest, symptoms recurred between two to four years after operation in four, and after four years in the remaining three. Despite early recourse to endoscopy in any symptomatic patient, there was often a delay of more than six months between the onset of symptoms and definitive diagnosis. All recurrences were in the duodenum except for one prepyloric ulcer and another in the pyloric canal. Ten have had additional ulcer surgery and the condition of four remains satisfactory on long-term cimetidine.

\section{G R O U P B}

This group consists of five patients, who we separate from the others because their recurrence has been of little significance to them. They all had a superficial ulcer in the duodenum associated with duodenitis diagnosed by endoscopy at the time of their recurrent symptoms. Three of these were taking gastric irritant drugs at the time. All remain well after a short course only of cimetidine and withdrawal of the drugs. We have chosen to describe this group as 'transient recurrence'.

\section{(; ROU P C}

This group contains another four patients who are undoubted failures with recurrent, severe epigastric pain related to meals. However, we have not been able convincingly to demonstrate re- current ulceration. All are dependent on cimetidine to control symptoms and one is inadequately controlled and additional surgery is planned.

Six patients had symptoms of gastric stasis. three requiring pyloroplasty and three satisfactorily controlled with metoclopramide. The remaining patients all have satisfactory results with few complications. Four patients have mild dumping symptoms easily controlled by diet, and four patients have mild diarrhoea.

\section{Discussion}

We have used proximal gastric vagotomy as the procedure of choice in the treatment of uncomplicated chronic ulcer in the last decade. The approach is logical and the operation feasible in the majority of patients, excluding the obese where the nerve to the antrum can be difficult to see. We have been impressed by the lack of complications which so often accompany most other operations for peptic ulcer. There are two reservations about the use of proximal gastric valgotomy: the frequency of recurrent ulceration which is likely to result from incomplete vagotomy, and the incidence of gastric stasis resulting from inadvertent damage to the nerve to the antrum.

There are numerous reports of the early results of proximal gastric vagotomy with an incidence of recurrent ulceration ranging from $2 \%^{;}$to $22 \%$." A five year postoperative follow-up is the minimum required to assess the value of any operation for peptic ulcer and in the Table we reproduce the results of the reports so far published." 12 together with our own results. In some reports the operation has sometimes been regarded as unsatisfactory, but no recurrent ulcer

Table Frequency of recurrent ulceration and failure to control ulcer symptoms five or more years after proximal gastric vagotomy

\begin{tabular}{|c|c|c|c|c|c|c|c|}
\hline \multirow[t]{2}{*}{ Author } & \multirow{2}{*}{$\begin{array}{l}\text { Patients } \\
\text { (no.) }\end{array}$} & \multicolumn{4}{|c|}{ Recurrence } & \multirow{2}{*}{\multicolumn{2}{|c|}{$\begin{array}{l}\text { Failed } \\
\text { operations } \\
(A+C) \\
(\text { no. })(\%)\end{array}$}} \\
\hline & & $\begin{array}{l}\text { A } \\
\text { Prov } \\
\text { (no.) }\end{array}$ & $e d$ & $\begin{array}{l}\text { B } \\
\text { Tran- } \\
\text { sient }\end{array}$ & $\begin{array}{l}\text { C } \\
\text { Sus- } \\
\text { pected }\end{array}$ & & \\
\hline Jordan (1979) & 35 & 2 & $5 \cdot 7$ & 2 & - & 4 & $11 \cdot 4$ \\
\hline $\begin{array}{l}\text { A mdrup et al } \\
(1978)^{3}\end{array}$ & 100 & 6 & 6.0 & 3 & 2 & 8 & $8 \cdot 0$ \\
\hline $\begin{array}{l}\text { Goligher et al. } \\
(1978)^{9}\end{array}$ & 117 & 5 & $4 \cdot 3$ & - & 13 & 18 & $15 \cdot 3$ \\
\hline $\begin{array}{l}\text { Liavag and } \\
\text { Roland (1979) }\end{array}$ & 182 & 19 & $10 \cdot 4$ & - & 3 & 22 & $12 \cdot 1$ \\
\hline Storey et al. (1981) & $\begin{array}{r}93 \\
527\end{array}$ & $\begin{array}{l}15 \\
47\end{array}$ & $\begin{array}{r}16 \cdot 1 \\
8 \cdot 9\end{array}$ & $\begin{array}{r}5 \\
10\end{array}$ & $\begin{array}{r}4 \\
22\end{array}$ & $\begin{array}{l}19 \\
71\end{array}$ & $\begin{array}{l}20 \cdot 4 \\
13 \cdot 5\end{array}$ \\
\hline
\end{tabular}

*To this figure must be added the $0-4 \%$ incidence of gastric stasis requiring additional surgery. 
identified. There is inconsistency in the method of reporting results, and we have used a method of classification which allows some comparison of the individual reports. Patients in group A are those with unequivocal recurrent ulceration, which in our practice was $16 \%$, while in others it ranged from $4.3 \%$ to $10 \cdot 1 \%$. Patients in group $B$ are defined as those with transient recurrent ulceration, responding to short-term medical treatment, and where the ulceration in some patients could be accounted for by the ingestion of gastric irritants. There were five patients in this group $(5 \cdot 3 \%)$, compared with $3 \%$ noted by Amdrup and $5.7 \%$ recorded by Jordan. Neither Goligher nor Liavag encountered similar patients. In group $C$ are patients where the operation has clearly failed and the patient has symptoms as severe as those before surgery. In Goligher's series this accounts for most of the failures of operation $(11.1 \%)$, though the incidence in other series is only $2-4 \%$. Some of our patients in this group are cimetidine dependent, though no recurrent ulcer has been identified. If we accept that patients from groups $\mathrm{A}$ and $\mathrm{C}$ represent unsatisfactory operations, then in our experience this is $20.4 \%$ failures, comparable with $15 \cdot 3 \%$ reported by Goligher. Other reports are more favourable, but the overall frequency of failure is $13.5 \%$ of all current five year follow-up reports.

The reasons for discrepancy in results may be technical. When first introduced, the operation had a limited dissection of $2-3 \mathrm{~cm}$ at the lower end of the oesophagus; this was later extended to 5-6 cm. "In the majority of patients who develop recurrence, symptoms appear within the first two to three years after operation. However, late onset of recurrence is not uncommon.

The other complications of gastric surgery for duodenal ulcer were notable by their absence. Only four of our patients suffered from dumping, which was easily controlled by dietary measures. None of the patients had bilious vomiting. Diarrhoea occurred in three and was intermittent and never associated with urgency. Reflux oesophagitis was found in two patients. Six patients had serious discomfort from gastric stasis, and three have required a drainage operation. In none of these patients was there evidence of pyloric stenosis and inadvertent damage to the antral nerve was regarded as the probable cause.

Our experience five to nine years after proximal gastric vagotomy must be viewed in the light of technical advance. An operative failure of $20.4 \%$ due to recurrent ulceration with another $3.2 \%$ due to gastric stasis is unsatisfactory. The high failure rate of $15 \cdot 3 \%$ noted by Goligher is apparently not due to recurrent ulceration, though even with the introduction of endoscopy this can be a difficult diagnosis to confirm. The overall proven recurrence rate in reported series is $8.9 \%$, and, although this is greater than the incidence after other forms of valgotomy, it would be acceptable. The higher overall frequency of unsatisfactory results $(13.5 \%)$ is of more concern and requires more detailed examination of the cause. At this stage there must be some reservations about the results of proximal gastric valgotomy.

\section{References}

'Dragstedt LR. Gastric vagotomy in the treatment of duodenal ulcer. In: Nyhus LM, Wastell C, eds. Surgery of the stomach and duodenum. Boston: Little, Brown 1977; 261-96.

'Humphrey CS, Johnston D, Walker BE, Pulvertaft CN, Goligher JC. Incidence of dumping after truncal and selective vagotomy with pyloroplasty and high selective vagotomy without drainage procedure. Br Med J 1972; 3:785.

${ }^{3}$ Amdrup E, Andersen D, Hostrup H. The Arhus County Vagotomy Trial. I. An interim report on primary results and incidence of sequelae following parietal cell vagotomy and selectve gastric vagotomy in 748 patients. World J Surg 1978; 2:85-9().

4 Jordan PH. An interim report on parietal cell vagotomy versus selective vagotomy and antrectomy for treatment of duodenal ulcer. Ann Surg 1979; 189:643-53.

"A mdrup E, Jensen HE, Johnston D, Walker BE, Goligher JC. Clinical results of parietal cell vagotomy (highly selective vagotomy) two to four years after operation. Ann Surg 1974; 180:279.

${ }^{8}$ Kronborg O, Jorgensen PM, Holst-Christensen J. Influence of different techniques of proximal gastric vagotomy upon risk of recurrent duodenal ulcer and gastric acid secretion. Acta Chir Scand 1977; 143:53-6.

Cumberland H, Coupland CAE. Parietal cell vagotomy. Chir Gastroenterol 1977; XI(4):383.

"Kronborg O, Madsen P. A controlled randomised trial of highly selective vagotomy vs. selective vagotomy and pyloroplasty in the treatment of duodenal ulcer. Gut 1975; 16:268.

"Goligher JC, Hill GL, Kenny TT, Nutter E. Proximal gastric vagotomy without drainage for duodenal ulcer: results after 5-8 years. Br J Surg 1978; 65: 145-51.

10Jensen H-E, Amdrup E. Follow up of 100 patients five to eight years after parietal cell vagotomy. World J Surg 1978; 2:525-32.

${ }^{11}$ Liavag I, Roland M. A seven year follow-up of proximal gastric vagotomy. Clinical results. Scand J Gastroenterol 1979; 14:49-56.

12Jordan PH. Our first thirty-five patients studied five years after parietal cell vagotomy. Arch Surg 1979; 114:528-34. 